\title{
Phenolic profile of seventeen Portuguese wild mushrooms
}

(1)

3

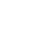

M. Helena Vasconcelos ${ }^{\mathrm{b}, \mathrm{c}}$ Isabel C.F.R. Ferreira ${ }^{\mathrm{ae}, \mathrm{e}}$

${ }^{a}$ CIMO- Montain Research Centre, Bragança, Portugal.

${ }^{b}$ FFUP - Faculty of Pharmacy of the University of Porto, Portugal

${ }^{c}$ IPATIMUP - Institute of Molecular Pathology and Immunology of the University of Porto, Portugal.

${ }^{d}$ CEQUIMED-UP - Center of Medicinal Chemistry, University of Porto, Portugal.

${ }^{e}$ Escola Superior Agrária, Instituto Politécnico de Bragança, Portugal.

*Corresponding author. e-mail: iferreira@ipb.pt, tel. $\quad+351273303219, \quad$ fax +351273325405 .

The work described has not been published previously; it is not under consideration for publication elsewhere; its publication is approved by all authors and tacitly or explicitly by the responsible authorities where the work was carried out; if accepted, it will not be published elsewhere including electronically in the same form, in English or in any other language, without the written consent of the copyright-holder. 
25 Analysis of phenolic compounds in seventeen Portuguese wild mushroom species was 26 carried out by high-performance liquid chromatography coupled to photodiode array 27 detection (HPLC-DAD). Protocatechuic, $p$-hydroxybenzoic, $p$-coumaric and cinnamic acid 28 were found and quantified. Fistulina hepatica showed the highest phenolic acids 29 concentration $(111.72 \mathrm{mg} / \mathrm{Kg}, \mathrm{dw})$ due to the significant contribution of protocatechuic $30 \quad(67.62 \mathrm{mg} / \mathrm{Kg})$ and $p$-hydroxybenzoic $(41.92 \mathrm{mg} / \mathrm{kg})$ acids. The edible mushrooms analyzed could be directly used in the human diet to combat oxidative stress, while inedible species could represent a source of extractable phenolic compounds to be used as additives in the food industry or as components in pharmaceutical and cosmetic 34 formulations, due to their well-known antioxidant properties.

Keywords: Wild mushrooms; edibility; phenolic compounds, HPLC-DAD. 


\section{Introduction}

The implication of oxidative and nitrosative stress in the etiology and progression of several acute and chronic clinical disorders such as cancer, cardiovascular and neurodegenerative diseases, has led to the suggestion that natural antioxidants may have health benefits as prophylactic agents. These antioxidants may help the endogenous defence system, assuming a major importance as possible protector agents reducing oxidative damage (Ferreira, Barros, \& Abreu, 2009). Against this background, the possibility of including mushrooms, which contain significant amounts of bioactive phytochemicals, in our diets may provide desirable health benefits, beyond that of basic nutrition.

The antioxidants found in mushrooms are mainly phenolic compounds, having been quantified in many different species mainly from Finland (Mattila et al., 2001), India (Puttaraju, Venkateshaiah, Dharmesh, \& Somasundaram, 2006; Jayakumar, Thomas, \& Geraldine, 2009), Korea (Kim et al., 2008), Portugal (Ribeiro et al., 2006; Ribeiro, Valentão, Baptista, Seabra, \& Andrade, 2007; Ribeiro et al., 2008; Barros, Dueñas, Ferreira, Baptista, \& Santos-Bulega, 2009) and Turkey (Yaltirak, Aslim, Ozturk, \& Alli, 2009). Phenolic compounds have specific health effects even though they are non-nutritive compounds. In our diet they might provide health benefits associated with reduced risk of chronic diseases which may relate to their ability to reduce agents by donating hydrogen and quenching singlet oxygen. Antioxidant properties of phenolic compounds also play a vital role in the stability of food products, as well as in the antioxidative defence mechanisms of biological systems (Wright, Johnson, \& DiLabio, 2001).

It is our interest to characterize the phenolic composition of mushroom species and to understand if differences exist between the phenolic profile of edible and non edible species. 
2. Materials and Methods

65

66

\subsection{Samples}

Seventeen mushroom species were collected in different ecosystems of the Northeast of Portugal (Table 1). The morphological identification of the wild macrofungi was made according to macro and microscopic characteristics (Marchand, 1971-1986; Bon, 1988; Courtecuisse \& Duhem, 2005). Representative voucher specimens were deposited at the herbarium of Escola Superior Agrária de Bragança. After taxonomic identification, the mushrooms were immediately lyophilized (Ly-8-FM-ULE, Snijders, Holland).

\subsection{Standards and reagents}

Acetonitrile 99.9\% was of HPLC grade from Lab-Scan (Lisbon, Portugal). Other solvents were of analytical grade purity and were also supplied by Lab-Scan. Phenolic standards were from Sigma Chemical Co. (St. Louis, MO, USA). Water was treated in a Milli-Q water purification system (TGI Pure Water Systems, USA) before use.

\subsection{Sample preparation}

Each mushroom sample ( $\sim 3 \mathrm{~g})$ was extracted using an acetone:water $(80: 20 ; 30 \mathrm{ml})$ mixture at $-20^{\circ} \mathrm{C}$ for $6 \mathrm{~h}$. After $15 \mathrm{~min}$ in an ultrasonic bath, the extract was centrifuged at $4000 \mathrm{~g}$ for $10 \mathrm{~min}$ and filtered through Whatman $\mathrm{n}^{\circ} 4$ paper. The residue was then extracted with two additional $30 \mathrm{ml}$ portions of the acetone:water mixture. The combined extracts were evaporated at $40{ }^{\circ} \mathrm{C}$ under reduced pressure to remove acetone (rotary evaporator Büchi R-210). The aqueous phase was washed with $n$-hexane and then submitted to a liquid-liquid extraction with diethyl ether $(3 \times 30 \mathrm{ml})$ and ethyl acetate $(3 \times 30 \mathrm{ml})$. The 
organic phases were evaporated at $40{ }^{\circ} \mathrm{C}$ to dryness, redissolved in water:methanol (80:20) and filtered through a $0.22 \mu \mathrm{m}$ disposable LC filter disk for HPLC analysis.

\subsection{HPLC analysis}

The phenolic extracts were analysed using HPLC equipment consisting of an integrated system with a Varian 9010 pump, a Varian Pro star diode array detector (DAD) and a Jones Chromatography oven column heater (model 7981). Data were analysed using Star chromatography workstation version 6.41 software (Varian). The chromatographic separation was achieved with an Aqua (Phenomenex, Torrance, CA) reverse phase $\mathrm{C}_{18}$ column $\left(3 \mu \mathrm{m}, 150 \mathrm{~mm} \times 4.6 \mathrm{~mm}\right.$ i.d.) thermostatted at $30^{\circ} \mathrm{C}$. The mobile phase and the gradient employed was described previously (Barros et al., 2009). Injection volume was 20 $\mu 1$. Detection was carried out in a diode DAD, using $280 \mathrm{~nm}$ as the preferred wavelength.

\section{Results and Discussion}

Protocatechuic, $p$-hydroxybenzoic, $p$-coumaric and cinnamic acids were identified and quantified in some of the analysed samples (Table 2) by comparing their chromatographic characteristics and absorption spectra with that of the standard compounds.

Fistulina hepatica showed the highest concentration of phenolic acids mostly due to the contribution of protocatechuic and $p$-hydroxybenzoic acids (Table 2). Mushrooms have developed chemical defence mechanisms (against insects and microorganisms) analogous to those in plants, such as the production of phenolic compounds. In fact, phenolic compounds have been shown to protect the plant cell wall during UV, salt, or pathogenic stress (Signore, Romeo, \& Giaccio, 1997). Indeed, other authors (Ribeiro et al., 2007) reported the presence of caffeic, p-coumaric and ellagic acids in Fistulina hepatica 
112 collected in the same region (Bragança, Portugal) in 2004. However, we did not find any of those phenolic compounds in our sample.

Instability of phenol content over time after collection is often observed, probably due to enzymatic and oxidative decomposition. This fact, together with the different stress conditions at which mushrooms were submitted, as well as the different extraction methodology applied (in addition to possible genetic variability) could explain the differences observed between the present study and other studies in what concerns the phenolic profile of Fistulina hepatica (Ribeiro et al., 2007) and Hydnum repandum (Puttaraju et al., 2006). In addition, in our study it was possible to detect and quantify cinnamic acid in a Portuguese sample of the latter mushroom, while other authors also quantified tannic, gallic and protochatecuic acids in a sample from India (Puttaraju et al., 2006).

No phenolic acids were detected in Laccaria amethystina, Lepista inversa and Russula delica. Nevertheless, Yaltirak et al. (2009) found gallic acid, catechin, caffeic acid and rutin in a sample of Russula delica from Turkey. These authors used an extraction methodology with ethanol in a soxhlet apparatus at $60{ }^{\circ} \mathrm{C}$. We avoided heat due to the fact that phenolic compounds are unstable and readily become non-antioxidative under heating and in the presence of antioxidants (Yen \& Hung, 2000; Barros, Baptista, Correia, Morais, \& Ferreira, 2007). However, the results obtained by Yaltirak et al. (2009) support the view that heat may increase phenolics concentration. Also, Choi, Lee, Chun, Lee, \& Lee (2006) described that heat treatment of Shiitake increased the overall content of free polyphenolic and flavonoid compounds. The authors explained that heat treatment might produce changes in their extractability due to the disruption of the plant cell wall - thus bound polyphenolic and flavonoid compounds may be released more easily relative to those of raw materials. 
137 Figure 1 compares the total phenolic compounds according to the edibility of each wild mushroom sample. Fistulina hepatica, Hygrophorus agathosmus, Tricholoma atrosquamosum and Suillus collinitus are edible mushrooms and showed the highest content of phenolics. Although the sample number of inedible mushrooms and mushrooms with questionable edibility was lower than that of the edible species, it can be concluded that Tricholoma sulphureum was the only inedible mushroom that yielded a reasonable phenolic content. Therefore, despite being inedible, mushrooms are an important source of phenolic compounds that could be extracted and included in formulations to prevent oxidative stress. This state in humans is originated by continuous exposure to chemicals and contaminants that lead to an increase in the amount of free radicals in the body, causing irreversible oxidative damage to biomolecules (e.g. lipids, proteins, DNA). Therefore, antioxidants and particularly phenolic compounds may decrease the risks of several chronic diseases such as atherosclerosis, cancer, diabetes, aging and other degenerative diseases in humans (Halliwell, 1996).

Overall, Fistulina hepatica revealed the highest concentration of phenolic compounds. The phenolic profile of this sample and of Hydnum repandum and Russula delica has already been described. However, we pointed out some differences in the results obtained. Furthermore, this is the first time that phenolic compounds in the other fourteen species are described. The edible mushrooms could be directly used in the human diet to combat oxidative stress, taking advantage on the synergistic and/or additive effects of all the compounds present therein (Liu, 2004), while inedible species could represent a source of extractable phenolic compounds to be used as additives in the food industry or as components in pharmaceutical and cosmetic formulations, due to their well-known antioxidant properties. 
Acknowledgements

The authors are grateful to FCT (I\&D 4040/2007, FEDER and POCI; BPD/4609/2008 grant to L. Barros and $\mathrm{BD} / 43653 / 2008$ grant to J.A. Vaz) for financial support, to Maria João Sousa and Sandrina Heleno for the collection and identification of the mushroom species. IPATIMUP is an Associate Laboratory of the Portuguese Ministry of Ministry of Science, Technology and Higher Education and is partially supported by FCT, the Portuguese Foundation for Science and Technology.

\section{References}

Barros, L., Baptista, P., Correia, D.M., Morais, J.S., \& Ferreira, I.C.F.R. (2007). Effects of Conservation Treatment and Cooking on the Chemical Composition and Antioxidant Activity of Portuguese Wild Edible Mushrooms. Journal of Agricultural and Food Chemistry, 55, 4781-4788.

Barros, L., Dueñas, M., Ferreira, I.C.F.R., Baptista, P., \& Santos-Buelga, C. (2009). Phenolic acids determination by HPLC-DAD-ESI/MS in sixteen different Portuguese wild mushrooms species. Food and Chemical Toxicology, 47, 10761079.

Bon, M. (1988). Guia de campo de los hongos de Europa. Ediciones Omega, Barcelona.

Courtecuisse, R., \& Duhem, B. (2005). Guía de los hongos de la Península Ibérica, Europa y Norte de África. Ediciones Omega, Barcelona.

Choi, Y., Lee, S.M., Chun, J., Lee, H.B., \& Lee, J. (2006). Influence of heat treatment on the antioxidant activities and polyphenolic compounds of Shiitake (Lentinus edodes) mushroom. Food Chemistry, 99, 381-387. 
Ferreira, I.C.F.R., Barros, L., \& Abreu, R.M.V. (2009). Antioxidants in wild mushrooms. Current Medicinal Chemistry, 16, 1543-1560.

Halliwell, B. (1996). Antioxidants in human health and disease. Annual Review of Nutrition, 16, 33-50.

Jayakumar, T., Thomas, P.A., \& Geraldine, P. (2009). In-vitro antioxidant activities of an ethanolic extract of the oyster mushroom, Pleurotus ostreatus. Innovative Food Science and Emerging Technologies, 10, 228-234.

Kim, M.Y., Seguin, P., Ahn, J.K., Kim, J.J., Chun, S.C., Kim, E.H., Seo, S.H., Kang, E.Y., Kim, S.L., Park, Y.J., Ro, H.M., \& Chung, I.M. (2008) Phenolic compound concentration and antioxidant activities of edible and medicinal mushrooms from Korea. Journal of Agricultural and Food Chemistry, 56, 7265-7270.

Liu, R.H. (2004). Potential synergy of phytochemicals in cancer prevention: mechanism of action. Journal of Nutrition, 134, 3479S-3485S.

Marchand, A. (1971-1986). Champignons du Nord et du Midi, Vols.1-9. Société Mycologique des Pyrénées Méditerranéennes, Perpignan.

Mattila, P., Konko, K., Eurola, M., Pihlava, J.M., Astola, J., Vahteristo, L., Hietaniemi, V., Kumpulainen, J., Valtonen, M., \& Piironen, V. (2001). Contents of vitamins, mineral elements, and some phenolic compounds in cultivated mushrooms. Journal of Agricultural and Food Chemistry, 49, 2343-2348.

Puttaraju, N.G., Venkateshaiah, S.U., Dharmesh, S.M., \& Somasundaram, R. (2006) Antioxidant activity of indigenous edible mushrooms. Journal of Agricultural and Food Chemistry, 54, 9764-9772.

Ribeiro, B., Lopes, R., Andrade, P.B., Seabra, R.M., Gonçalves, R.F., Baptista, P., Quelhas, I., \& Valentão, P. (2008). Comparative study of phytochemicals and 
antioxidant potential of wild edible mushroom caps and stipes. Food Chemistry, $110,47-56$.

Ribeiro, B., Rangel, J., Valentão, P., Baptista, P., Seabra, R.M., \& Andrade, P.B. (2006). Contents of carboxylic acids and two phenolics and antioxidant activity of dried portuguese wild edible mushrooms. Journal of Agricultural and Food Chemistry, $54,8530-8537$.

Ribeiro, B., Valentão, P., Baptista, P., Seabra, R.M., \& Andrade, P.B. (2007). Phenolic compounds, organic acids profiles and antioxidative properties of beefsteak fungus (Fistulina hepatica). Food and Chemical Toxicology, 45, 1805-1813.

Signore, A.D., Romeo, F., \& Giaccio, M. (1997). Content of phenolic substances in basidiomycetes. Mycological Research, 5, 552-556.

Wright, J.S., Johnson, E.R., \& DiLabio, G.A. (2001). Predicting the activity of phenolic antioxidants: theoretical method, analysis of substituent effects, and application to major families of antioxidants. Journal of the American Chemical Society, 123, $1173-1183$.

Yaltirak, T., Aslim, B., Ozturk, S., \& Alli, H. (2009). Antimicrobial and antioxidant activities of Russula delica Fr.. Food and Chemical Toxicology, 47, 2052-2056.

Yen, G.-C., \& Hung, C.-Y. (2000). Effects of alkaline and heat treatment on antioxidative activity and total phenolics of extracts from Hsian-tsao (Mesona procumbens Hemsl.). Food Research International, 33, 487-492. 
Table 1. Information on the wild mushroom samples collected.

\begin{tabular}{llll}
\hline Species & Common name & Edibility & Ecossystem \\
\hline Fistulina hepatica (Schaeff.:Fr.) & Beefsteak Fungus & Edible & Quercus pyrenaica \\
Hydnum repandum (L.: Fr.) & Hedgehog & Edible & Mixed stands \\
Hygrophoropsis aurantiaca (Wulf.: Fr.) Mre. & False Chanterelle & Questionable & Mixed stands \\
Hygrophorus agathosmus & Gray almond waxy cap & Edible & Mixed stands \\
Hygrophorus olivaceo-albus & None & Edible & Mixed stands \\
Laccaria amethystina (Bolt. ex Fr.) R.Maire & Amethyst Deceiver & Edible & Quercus pyrenaica \\
Lactarius aurantiacus (Fr.) & Orange milkCap & Edible & Mixed stands \\
Lactarius salmonicolor (Heim y Leclair) & None & Edible & Quercus pyrenaica \\
Lepista inversa (Scop.: Fr.) & Tawny funnel cap & Edible & Mixed stands \\
Mycena haematopus (Pers) P. Kumm. & Bleeding mycena & Questionable & Mixed stands \\
Russula caerulea (Pers) Fr. & Humpback brittlegill & Edible & Pinus pinaster \\
Russula delica (Fr.) & Milk-white brittlegill & Edible & Mixed stands \\
Russula sardonia Fr. & Primrose brittlegill & Inedible & Pinus pinaster \\
Suillus collinitus (Fr.) Kuntz & None & Edible & Quercus pyrenaica \\
Suillus mediterraneensis (Jacquetant \& Blum) Redeuilh & None & Inedible & Quercus pyrenaica \\
Tricholoma atrosquamosum (Cheval) sacc. & None & Edible & Mixed stands \\
Tricholoma sulphureum (Bull.: Fr.) Kumm. & Sulphur knight & Inedible & Quercus pyrenaica \\
\hline
\end{tabular}


Table 2. Phenolic acids (mg/Kg dw) found in the mushroom samples (mean \pm standard deviation; $\mathrm{n}=3$ ).

\begin{tabular}{|c|c|c|c|c|c|}
\hline & $\begin{array}{l}\text { protocatechuic acid } \\
(22.3 \mathrm{~min})\end{array}$ & $\begin{array}{c}p \text {-hydroxybenzoic acid } \\
(33.4 \mathrm{~min})\end{array}$ & $\begin{array}{c}p \text {-coumaric acid } \\
(52.3 \mathrm{~min})\end{array}$ & $\begin{array}{l}\text { cinnamic acid } \\
(63.7 \mathrm{~min})\end{array}$ & Total phenolic acids \\
\hline Fistulina hepatica & $67.62 \pm 1.66$ & $41.92 \pm 8.95$ & nd & $2.16 \pm 0.10$ & $111.72 \pm 7.19$ \\
\hline Hydnum repandum & nd & nd & nd & $4.51 \pm 1.25$ & $4.51 \pm 1.25$ \\
\hline Hygrophoropsis aurantiaca & nd & nd & nd & $3.52 \pm 0.88$ & $3.52 \pm 0.88$ \\
\hline Hygrophorus agathosmus & $17.92 \pm 0.20$ & nd & $8.65 \pm 0.20$ & $46.04 \pm 0.23$ & $72.61 \pm 0.62$ \\
\hline Hygrophorus olivaceo-albus & nd & $7.38 \pm 0.19$ & nd & $0.85 \pm 0.15$ & $8.23 \pm 0.44$ \\
\hline Laccaria amethystina & nd & nd & nd & nd & nd \\
\hline Lactarius aurantiacus & nd & nd & nd & $9.18 \pm 0.55$ & $9.18 \pm 0.55$ \\
\hline Lactarius salmonicolor & nd & $3.40 \pm 0.42$ & nd & $2.64 \pm 0.14$ & $6.04 \pm 0.29$ \\
\hline Lepista inversa & nd & nd & nd & nd & nd \\
\hline Mycena haematopus & $1.02 \pm 0.06$ & nd & nd & $2.96 \pm 0.03$ & $3.98 \pm 0.03$ \\
\hline Russula caerulea & nd & nd & nd & $2.58 \pm 0.04$ & $2.58 \pm 0.04$ \\
\hline Russula delica & nd & nd & nd & nd & nd \\
\hline Russula sardonia & nd & nd & nd & $0.43 \pm 0.01$ & $0.43 \pm 0.01$ \\
\hline Suillus collinitus & $5.18 \pm 0.21$ & $14.14 \pm 1.15$ & nd & $1.34 \pm 0.17$ & $20.66 \pm 1.12$ \\
\hline Suillus mediterraneensis & $1.38 \pm 0.09$ & $2.04 \pm 0.08$ & nd & $0.98 \pm 0.09$ & $4.40 \pm 0.26$ \\
\hline Tricholoma atrosquamosum & nd & nd & $79.34 \pm 4.51$ & $7.43 \pm 0.42$ & $86.67 \pm 4.10$ \\
\hline Tricholoma sulphureum & nd & $2.55 \pm 0.17$ & nd & $23.18 \pm 0.85$ & $25.73 \pm 1.03$ \\
\hline
\end{tabular}

nd- not detected 


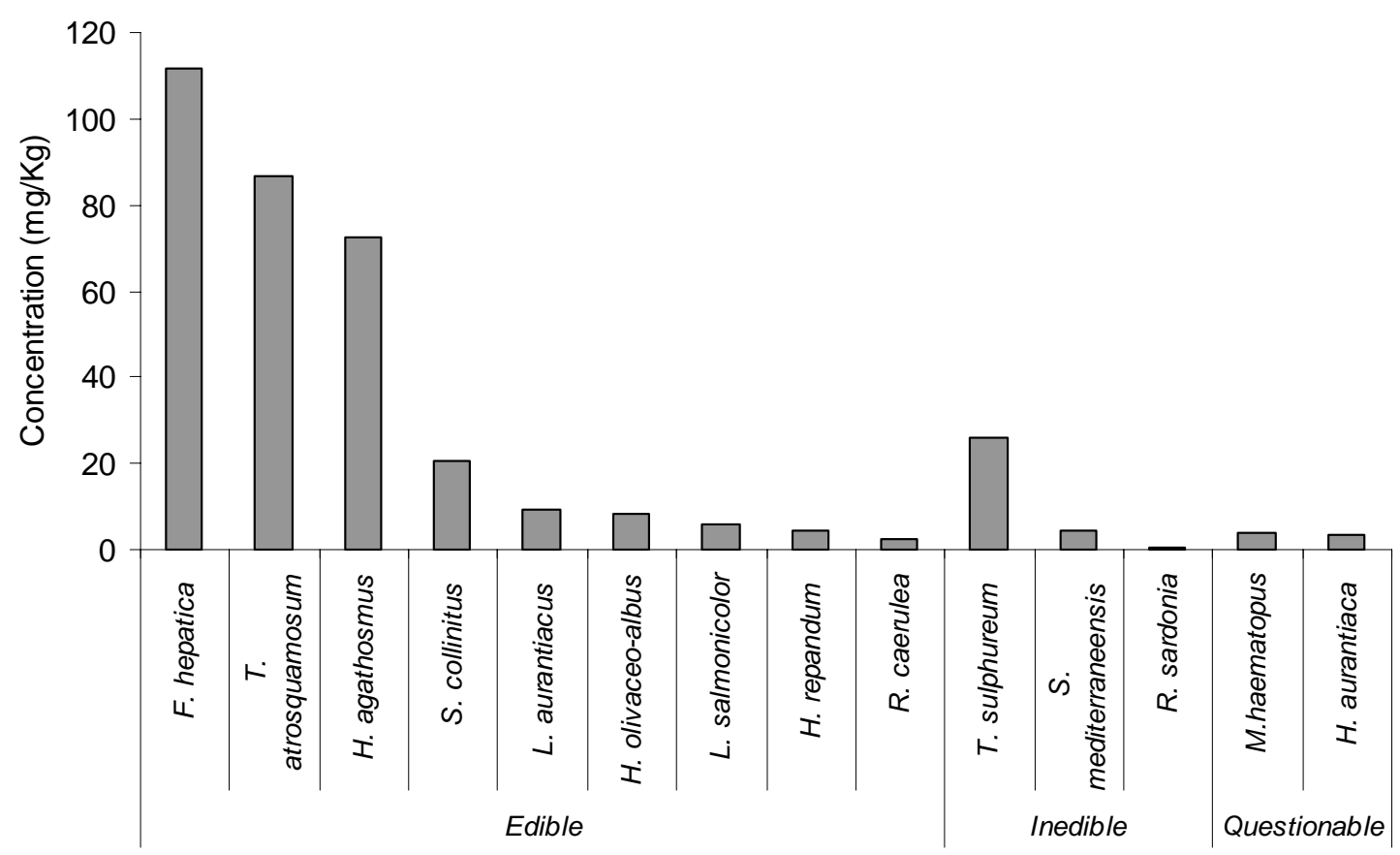

Figure 1. Comparison of phenolic acids content according to edibility of the wild mushrooms. 